Article

\title{
The Unknown Potential of Blockchain for Sustainable Supply Chains
}

\author{
Vincenzo Varriale, Antonello Cammarano * , Francesca Michelino and Mauro Caputo \\ Department of Industrial Engineering, University of Salerno, 84084 Fisciano, Italy; vvarriale@unisa.it (V.V.); \\ fmichelino@unisa.it (F.M.); mcaputo@unisa.it (M.C.) \\ * Correspondence: acammarano@unisa.it
}

Received: 11 October 2020; Accepted: 9 November 2020; Published: 12 November 2020

\begin{abstract}
The growing attention to emerging technologies has raised several doubts regarding the sustainability aspects. Among the new technologies, blockchain has laid the foundations for a revolution in the financial field but also in the energy, tourism, medical, industrial and supply chains sectors. Through a systematic literature review, 37 documents were analyzed to describe the sustainable aspects generated using blockchain in supply chains. Therefore, the results achieved provide two levels of analysis. The former highlights the impact of the adoption of blockchain in supply chains based on the three dimensions of sustainability: environmental, economic and social. The latter shows the positive and negative impacts of each form of sustainability. The purpose of the work is to summarize the current state of the art in order to propose a future development agenda based on the need to simulate and define a measurability for each dimension of sustainability. Finally, the study provides a broad overview of practical and managerial implications for entrepreneurs and researchers. On the one hand, the work shows how the use of blockchain improves the profits and reputation of companies. On the other hand, it highlights several research gaps to be investigated and considered by researchers.
\end{abstract}

Keywords: blockchain; supply chain; environmental sustainability; economic sustainability; social sustainability

\section{Introduction}

In the last five years, great interest has been focused on the use of emerging technologies to improve the sustainability issues of supply chains. This article concerns the use of blockchain technology within supply chains with a focus on the development of sustainable aspects. Blockchain technology was founded in 2008 by Satoshi Nakamoto [1] to solve the problem of exchanging coins. As the use of blockchain has expanded, both entrepreneurs and academics have become very interested in such technology. The first blockchain platform was Bitcoin [2] which allowed to exchange money with a specific consensus mechanism. Subsequently other platforms were born including Ethereum [3] - which allows the use of smart contracts, i.e., tools capable of activating automatically when an event occurs-and Hyperledger, created by IBM [4]. The potential of blockchain is high; therefore, many other applications arose in several areas including energy [5], real estate [6], tourism [7], smart city [8], e-voting [9], medical [10], industrial [11] and supply chain [12]. The article aims to classify the use of blockchain in sustainable and unsustainable aspects within the supply chains. Some scholars claim that blockchain can be a tool for achieving the United Nations Sustainable Development Goals [13]. In fact, some practices carried out in a traditional way are no longer sustainable, and digital tools such as blockchain are needed to improve environmental, economic and social sustainability [14]. The concept and use of distributed ledgers are increasingly associated with supply chains applications to solve many information sharing problems [15-17]. In particular, one of the very trendy and pioneering distributed 
ledger technologies for supply chains is blockchain technology. Recently, several academics have addressed the benefits and challenges of blockchain technology in supply chains [18-20]. Unlike other distributed ledgers, blockchain integrates perfectly with other emerging technologies such as smart contracts [21], artificial intelligence [22], sensors [23], Internet of Things (IoT) [24] and machine learning [25]. Indeed, blockchain changes the way transactions and data are managed. In this way, it is possible to guarantee greater accuracy [26], greater control [27], greater security [19,28] and immediate sharing [23,29]. In addition, products can be traced in the supply chain [30], guaranteed origin and provenance of products [31], verify compliance and manage logistics by sharing operations data in real time [32]. Therefore, many start-ups have decided to invest in this technology, but will it really be able to revolutionize traditional processes? Will it improve the sustainable issues arose in recent years? Blockchain development is still in its infancy, so academics have used multi-criteria methods based on qualitative assessments to evaluate the advantage or disadvantage of this technology $[26,33,34]$.

The literature has strongly focused on the binomial blockchain and supply chain. Indeed, today, emerging technologies are evaluated in terms of innovation/business performance. However, in addition to business performance, it would also be necessary to carry out an assessment in terms of sustainability. Therefore, the purpose of the work is to present a systematic a systematic literature review (SLR) that portraits the current state of the art in order to verify the nature of the impacts of blockchain technology on sustainability in supply chains. Therefore, while scientific research and companies are trying to evaluate the usefulness and effectiveness of blockchain adoption in supply chains [26-28], this work wants to add a further element that could be useful in evaluating the adoption of this distributed ledger, in particular its impact in terms of sustainability. In fact, these evaluations could be added to the considerations of effectiveness and applicability in operational and technical terms, which are still being evaluated by researchers and companies [30-32]. This study aims to offer a research agenda on the use of blockchain in supply chains to support and improve sustainability based on its three dimensions: environmental, social and economic. In a second step, the advantages and criticalities of adopting blockchain technology in supply chains will be highlighted from the point of view of sustainability. The paper proposes the analysis of 37 articles from 2008 to 2020. Before showing the SLR, a theoretical background chapter presents a summary on the recently explored link between blockchain and the supply chain to highlight the exploitation of this technology. In order to present the technological features of blockchain, an overview of what are the positive and negative factors that may be associated with the adoption of this distributed ledger is provided. However, these factors are still being evaluated by the scientific literature that is analyzing and studying the technology [18-20]. Subsequently, the following sections show the methodology and the results achieved. Then, the three dimensions of environmental, economic and social sustainability and the sustainable and unsustainable aspects of blockchain within supply chains are discussed. Finally, discussions and conclusions close the work.

\section{Theoretical Background}

Recently, blockchain emerged as a new way of exchanging money. However, the mechanisms that such technology uses are revolutionizing social and economic dynamics. Indeed, Gartner ranked blockchain as one of the top ten strategic technologies for 2020 [35]. However, in that report, the technology was reported as in the "Trough of Disillusionment" phase, since interest had decreased as experiments and implementations failed to achieve relevant performance. Despite this, blockchain can be considered a new paradigm of information and data exchange, which is considered crucial in several area [36]. Therefore, interest has grown in many sectors including supply chains. One of the biggest reasons for using blockchain within supply chains is its capability to have a constantly updated and secure distributed ledger on product tracking $[22,33]$. Thanks to its consensus mechanism, in order to introduce specific information, blockchain controls access and immediately intercepts fraudulent and incorrect data [37]. On the one hand, this guarantees the authentication and certification of an asset to the final consumer; on the other one, it eliminates the use of intermediaries and automates the 
certification system $[26,38]$. Indeed, another crucial tool is the use of smart contracts that automate several events that would take time [39]. The fields mainly observed and studied are agri-food [40], logistics [28] and shipping [41]. In recent years, in addition to the industry 4.0 plans, the idea of agriculture 4.0 has been advancing [22]. Many studies are addressing the problem of decision-making processes in the agri-food supply chain by exploiting new technologies. For example, tracking and control technologies—such as drones and sensors—can be exploited to monitor agri-food products. Finally, evaluations could be conducted on the data collected through blockchain [22,42]. Furthermore, especially for food products, blockchain guarantees trust to the final consumers because it is an immutable register, verifiable by anyone in real time [27]. The transparency and visibility of the products generates trust in the purchase of the product [31]. As for logistics and shipping, blockchain will be able to speed up cross-border shipping processes [43], reducing bureaucracy and paperwork at customs through the use of smart contracts and guaranteeing the origin and provenance of the products [44]. Several projects have been launched including Tradelens [45] for maritime logistics and Mediledger [46] for the drug supply chain.

Before proceeding with the SLR on the evaluation of sustainability of blockchain within supply chains, this section will explore the intrinsic peculiarities of this distributed ledger.

The blockchain aims to be a secure tool for exchanging money within the internet without the use of central authorities and trusted parties. This distributed ledger relies on fundamental mechanisms such as cryptography, distributed nature and immutability in order to secure transactions within the network $[12,27,29]$. All these features allow cyber-attacks that could change events within the system to be avoided and significantly reduced [28]. Starting from these technological characteristics, the blockchain can be considered a new paradigm for the organizational change of supply chains. First of all, being able to track and monitor goods, documents and any other activity would allow the partners of the supply chain to reduce the risk of fraud among the participants [22,30]. In fact, each participant must adhere to well-defined protocols and must be authenticated and certified in the network using keys [26,47]. This mechanism is absent in the management of the Bitcoin network but it is necessary within the supply chain network to eliminate cyber-attacks such as sybil attack and ID spoofing [48]. Furthermore, the transactions recorded within the blockchain cannot be removed thanks to the hash pointer mechanism that binds the blocks [49]. Therefore, these peculiarities guarantee complete transparency and visibility regarding the exchanges of products between the players in the supply chain [23]. Finally, in terms of reliability and efficiency, this technology makes it possible to securely collect the exchanges of information within the ledger; it also increases the knowledge of each actor on the managerial operations of the network and guarantees less time consumption in managing operations [26,50]. Therefore, these features generate trust in the exploitation of the technology (Figure 1).

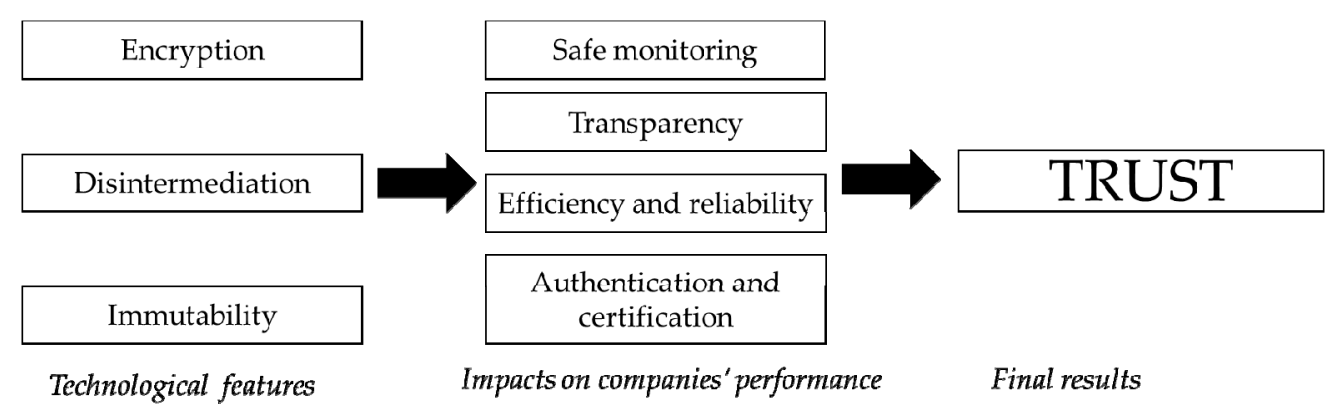

Figure 1. Advantages of using blockchain as a distributed ledger for supply chains.

However, this technology has factors that hinder its adoption. First, there is the problem of its technological performance in terms of scalability, latency, throughput and storage data [51,52]. As the number of nodes in the network increases, the increase in data within the ledger would result in an increase in database management and consultation times. In addition, writing operations intended as 
the registration of a block within the register can affect long waiting times. For this reason, the system could have some misalignments with the current state of operations [30]. It is necessary to take into account the costs of implementing and maintaining the distributed ledger within the network, which can affect small- and medium-sized enterprises in the supply chain $[27,30]$. Furthermore, one of the main problems is the lack of knowledge of the managers [53]. There are few real cases in which this technology has been used and its real potential is unknown. Finally, there are still no standards and regulations on the use of this technology [45]. Therefore, adoption is still low in the supply chains (Figure 2).

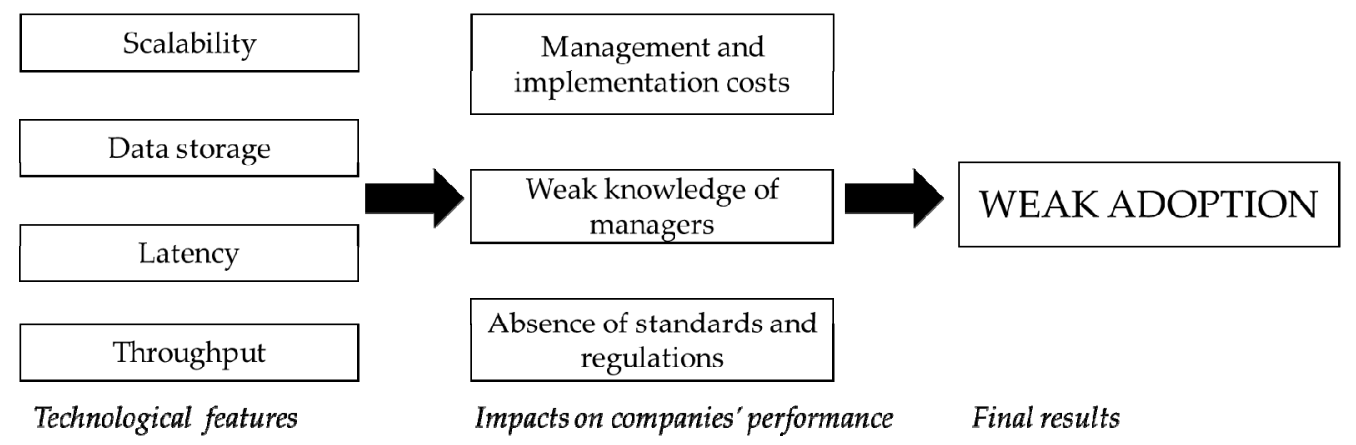

Figure 2. Disadvantages of using blockchain as a distributed ledger for supply chains.

In the next section, an overview of the impacts that the main characteristics of blockchain technology on the different forms of sustainability in the supply chains will be provided.

\section{Materials and Methods}

The methodology used to analyze the dynamics of sustainability in the blockchain world, and subsequently in supply chains, is the SLR. This is a well-established method that guarantees the verifiability and traceability of the procedure by the reviewers [54]. The research was conducted from 2008, the year in which blockchain exploded, until 2020. The Scopus database, containing the major international journals, is used to standardize the research. In addition, management journals have been selected to focus attention on the managerial and engineering side.

As shown in Figure 3, the methodology is divided into several operational steps:

1. A first search string TITLE-ABS-KEY ("Blockchain" AND "Sustainability") was used within Scopus to clarify the use of technology in terms of sustainability in several fields. The search identified 81 articles.

2. Reading the titles and abstracts of the various articles, an initial classification was made in authors, title, journal, year of publication, sector, case study, topic and objectives.

3. A second search string TITLE-ABS-KEY ("Blockchain" AND "Sustainability" AND "Supply Chain") was used within Scopus to define the use of technology within supply chains from the point of view of the sustainability. The search identified 37 articles.

4. Starting from this selection, sustainability has been detailed in its three dimensions: environmental, economic and social. Sustainable and non-sustainable aspects were assessed for each of them.

Figure 4 shows the number of articles published by year: the trend suggests increasing attention in journals with high impact factors since 2018. In Table 1, such journals are reported. 


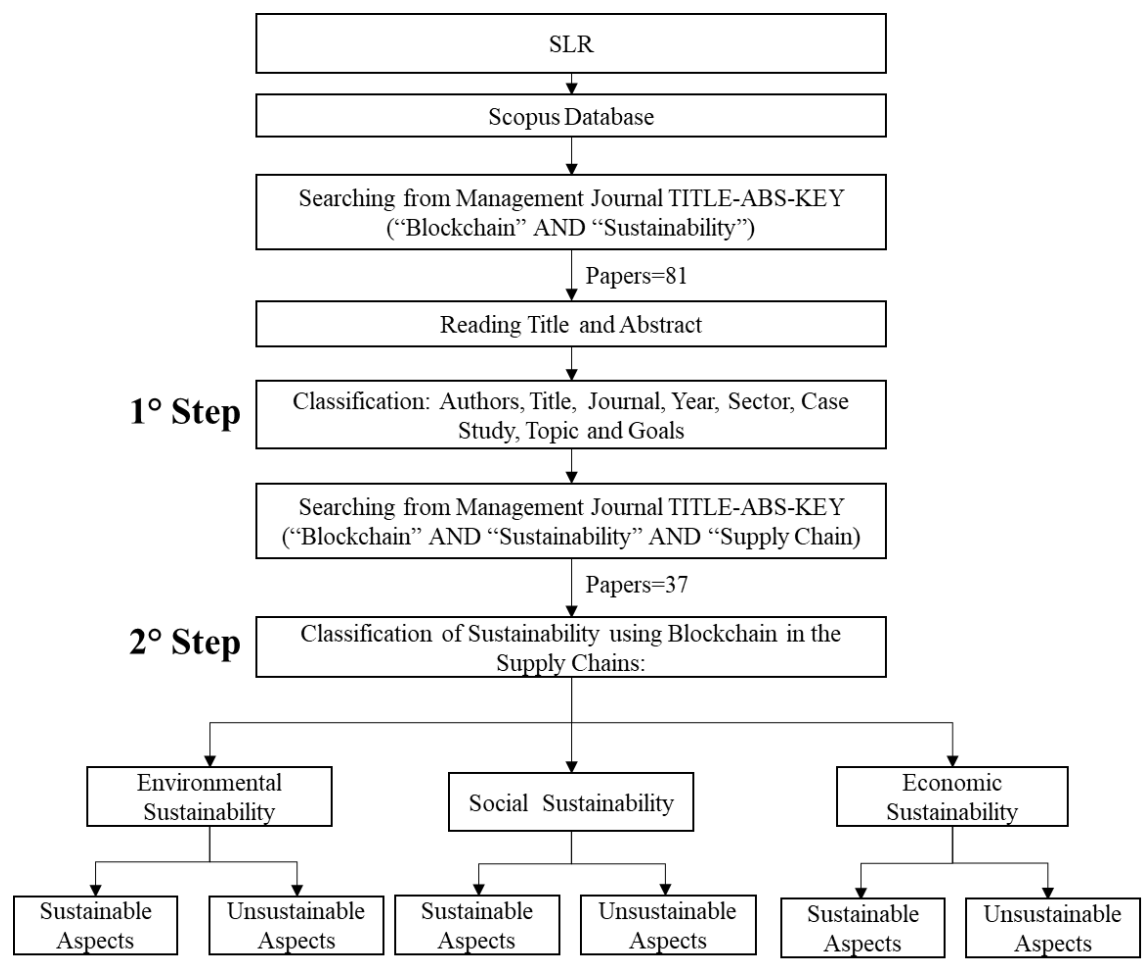

Figure 3. Systematic literature review (SLR) process.

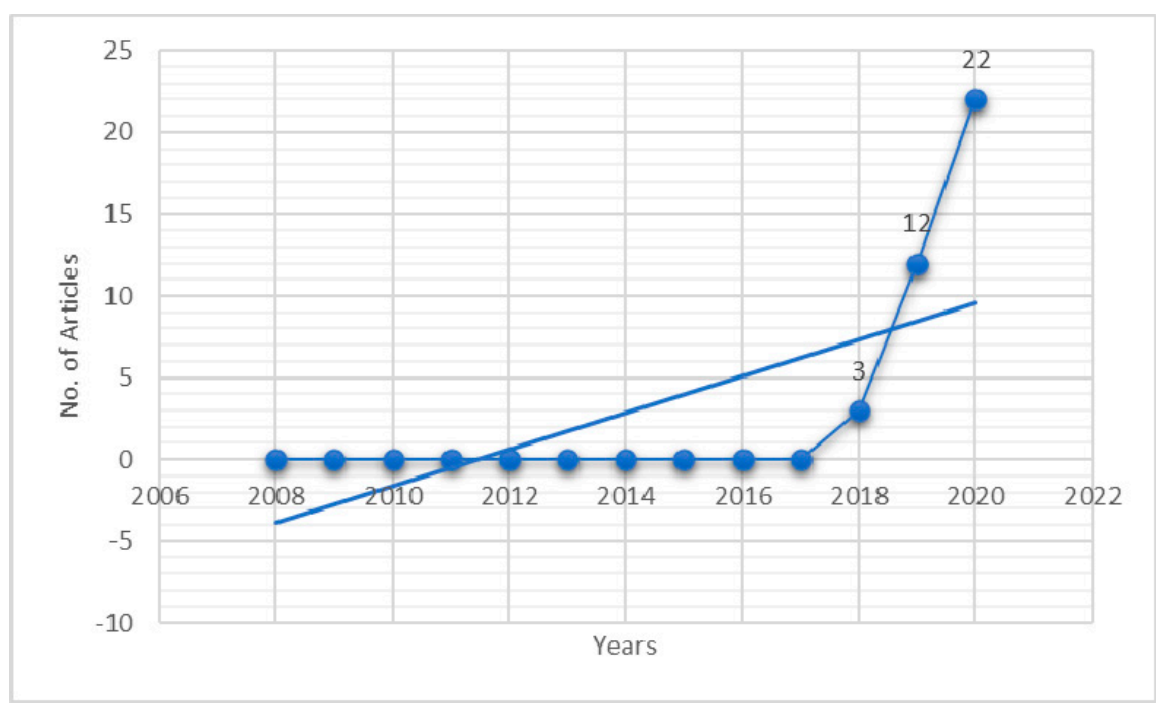

Figure 4. Summary of selected papers by year.

Table 1. Journal-wise distribution of selected papers.

\begin{tabular}{cc}
\hline Journal Name & \# Articles \\
\hline Sustainability & 9 \\
International Journal of Production Research & 4 \\
International Journal of Information Management & 3 \\
Resources, Conservation \& Recycling & 3 \\
Computers \& Industrial Engineering & 2 \\
International Journal of Production Economics & 2 \\
Supply Chain Management: An International Journal & 2 \\
Transportation Research Part E & 2 \\
\hline
\end{tabular}


Table 1. Cont.

\begin{tabular}{cc}
\hline Journal Name & \# Articles \\
\hline Applied Sciences & 1 \\
Computers and Operations Research & 1 \\
IFAC-PapersOnLine & 1 \\
Journal of Cleaner Production & 1 \\
Marine Policy & 1 \\
Production and Operations Management & 1 \\
Production Planning \& Control & 1 \\
Robotics and Computer Integrated Manufacturing & 1 \\
Soft Computing & 1 \\
Trends in Food Science \& Technology & 1 \\
\hline Total & 37 \\
\hline
\end{tabular}

\section{Results}

\subsection{Environmental Sustainability}

Blockchain can help sustainable practices within supply chains in several ways. Blockchain is a distributed and immutable ledger where transactions cannot be eliminated. This allows a complete tracking of every single activity in order to be constantly verifiable and controllable [49]. In fact, the transparency obtained by tracing products from their origin to the final consumer can reduce the carbon footprint and unsustainable practices [50]. Indeed, vehicle emission monitoring technologies, such as infrared sensors, are able to measure concentrations of greenhouse gas emissions [26]. Thanks to new technologies including the IoT, it is possible to transfer this information securely within the blockchain. When the transactions are entered the distributed ledger, they are definitively tamperproof [30]. Therefore, it is possible to quickly identify the vehicles involved in the supply chains that emit the highest levels of greenhouse gases and consequently implement sudden measures [24]. In recent years, attention has been growing on green logistics, which refers to the planning, control and implementation of the logistics flow using modern techniques and technologies with the aim of minimizing impacts on the environment. One of these techniques is the vehicle routing which makes it possible to optimize vehicle routes in real time to avoid traffic and reduce carbon emissions. By combining the different technologies including sensors, IoT and blockchain, all shipping requirements and specifications will be recorded in the distributed ledger and users will be able to use them and set energy optimization goals [55]. Furthermore, not only the tracking of vehicles but also their performance evaluation is important. For example, truck drivers may engage in bad driving behavior for convenience. Some of these behaviors can cause environmental damage; for example, driving faster increases emissions and fuel consumption. Changing driver behavior is a way to save energy resources and improve driving safety. Therefore, a solution could include the use of blockchain based on tokens that reward the constant performance of the driver and ensure safe and ecological practices. Most current incentive systems aim to deliver products quickly to their destination and, furthermore, the driver is only rewarded when driving specific distances. However, these incentives produce dangerous and unsustainable practices, as drivers accelerate more often and drive longer than working hours, creating dangerous conditions. Thanks to blockchain and the use of smart contracts, payment for the driver would be immediate and a constant monitoring of the vehicle performance can be achieved [56].

Another practice that can be improved within the supply chains is the waste management. Usually, people and organizations have little motivation to participate in recycling programs. Blockchain could motivate people through financial rewards in the form of tokens in exchange for storing recyclable materials such as plastic containers, bottles or paper [57]. Blockchain facilitates and speeds up the exchange of money, moreover, transactions are permanently recorded in the network in order to be checked. Using this technology would create a reputation-based system that encourages all the 
participants to improve environmental practices as they receive both an economic benefit and a reputation improvement [53]. Furthermore, blockchain enables the monitoring of dangerous waste, distributing responsibility to the participants of the system [58]. In particular, smart contracts can further facilitate waste exchanges by automatically executing procedures based on factors such as: the condition of the waste, its volume and quality. Moreover, sensors and tracking devices can detect the location of waste and make data available on blockchain ledgers [59]. This would ensure the reduction of fraud and greatly improve environmental safety.

Blockchain allows to improve circular economy practices. Product lifecycle transparency provides enterprises with critical knowledge to reconsider the product use and to redesign the products at the end of their lifecycle [60]. Companies can use this information to evaluate the circularity performance of their supply chains. For example, information on the production and use of a product that is constantly and accurately monitored can provide data on energy consumption [57]. Therefore, blockchain could analyze the energy consumption of products to provide decisions on any product or process eliminations to improve energy efficiency. Products with high energy consumption and low energy efficiency could be candidates for elimination in order to improve the circular economy. This system could help companies to identify materials and products that use non-renewable resources and remove them or invest in alternative green resources [59].

Finally, from the point of view of environmental sustainability, blockchain can allow better monitoring of the conservation of water and other resources for the agri-food industry. Data analysis guarantees food safety and ecological sustainability [25]. Furthermore, it is essential that food supply chains do not waste resources, especially in the agri-food sector. In particular, recording the use of the amount of water and other resources such as fertilizers can improve environmental management in order to ensure greater health of the soil and plants [24]. This information is easily verified by consulting the blockchain.

On the other hand, blockchain creates some problems in environmental terms. One of the main sustainability problems of blockchain is its energy consumption. The high computing power required for the proof-of-work consensus system consumes many hundreds of megawatts of energy [61]. Higher energy consumption also means higher carbon emissions. Decentralized ledgers also require more computing power and resources to maintain data security which leads to higher energy consumption [62]. The activity that makes energy consumption expensive is "mining", meaning that it requires more and more hardware resources to work [63]. Furthermore, energy consumption can increase significantly based on the algorithms used and the length of the smart contracts [57]. It is unclear whether mining will be necessary for supply chain activities. However, storage and operations will require significant energy needs for electronic supply chain databases as multiple data storage will potentially produce exponentially greater energy needs [56]. To mitigate the problem of energy consumption, another consensus protocol called "Proof of Stake" is considered: in this case, energy consumption is reduced but the privacy and security problems of the system increase [64].

Table 2 summarizes the possible advantages and disadvantages of the environmental sustainability issues that blockchain can include in the supply chains.

Table 2. Sustainable and unsustainable environmental issues of blockchain in supply chains.

\begin{tabular}{ccc}
\hline & Environmental Sustainability & References \\
\hline Sustainable Aspects & Monitoring and reduction of the carbon emissions & {$[24,30,33,46,49,50]$} \\
& Waste Management & {$[53,55-57]$} \\
& Circular Economy & {$[53,55,58]$} \\
Unsustainable Aspects & Conservation of resources & {$[50,59]$} \\
& Energy Consumption & {$[24,25,55,60-62]$} \\
\hline
\end{tabular}




\subsection{Economic Sustainability}

Although in the past sustainability has been seen as a cost for supply chains and in particular for logistics, today it is considered as a key factor of efficiency and profitability [55]. The logistics industry must manage logistics activities and processes effectively and efficiently, reducing costs and the negative impact on the environment and society. Blockchain can solve some supply chain problems and improve economic sustainability. Surely, the adoption of blockchain is suitable for big organizations. These companies will have more resources, greater transaction volumes, distributed operations in several places, numerous supply chain partners and more information to manage than smaller organizations. However, the impact on small organizations should not be overlooked since they must play their part within the network in supply chains in order to achieve real transparency [13]. The inclusion of several players in the network will ensure closer collaboration between the companies participating and increase their profitability [65]. By adopting blockchain, it is possible to create a peer-to-peer collaborative market, which allows to trade while avoiding fraud or opportunistic behaviors [55]. For this reason, companies that adopt blockchain will be able to verify information on their suppliers more efficiently and monitor that all participants adhere to sustainability practices. In this way, it is possible to guarantee a competitive advantage to the companies in the network. Indeed, environmental performance measurement systems will be critical in determining critical suppliers within the supply chain. It will be possible to distinguish green suppliers from those who do not operate with sustainable practices [26]. In fact, suppliers and sub-suppliers are invisible actors for the final customer, but they can become environmentally risky members and could provide low performance to the supply chain. In this way, it is also possible to identify which ecological supports the suppliers need [66]. Furthermore, the knowledge that is exchanged between suppliers can be registered in the blockchain through smart contracts. The information recorded provides measurement of the performance of supplier development programs. Therefore, this can also generate the selection of green and sustainable suppliers [26,67].

As for sustainable supply chain operations, blockchain can improve order fulfillment, distribution, payment for goods, communication of information. Blockchain can solve several supply chain problems such as: real-time communication, fast payment processing with reduced transaction fees, lower product costs, reduced delivery times $[26,53]$. Transparency allows the monitoring of products and processes, from origin to the final consumer, in terms of information such as: price, date, location, quality, certifications. Furthermore, the blockchain can reduce potential losses due to human error and the use of unnecessary bureaucratic activities [26]. A typical example of the traceability in the supply chains is the food industry. In general, the counterfeit foods are a threat to the public health. Effective management of the food supply chain is crucial to solve food safety problems. For example, in the case of a foodborne illness epidemic, the retailers need to trace the source of contamination and other affected products. Data such as farm origin, batch numbers, factory and processing data, expiration dates and shipping details can be written to the blockchain and made available to all the network members [51]. Additionally, increasing transparency in the supply chain can decrease the amount of food that is wasted after purchase and decrease the waste that occurs in food supply chain operations [24].

Thanks to the peculiarity of disintermediation, the blockchain can reduce costs and transaction times, reducing waste in the supply chain [59]. In addition, blockchain can ensure data security and authenticity, which will reduce the cost of preventing data from being deliberately tampered with by increasing supply chain risks and reducing business reliability [53].

Managing product information and market forecasts is a great tool for reducing costs. The blockchain can be used in inventory management, ensuring accounting and scheduling of clients' assets and transactions. This would ensure a sustainable B2B supply chain system. Therefore, the use of blockchain will improve productivity, reduce the time spent on process control, increase competitiveness and provide B2B companies with additional profits [68]. 
On the other hand, the adoption of blockchain in supply chains generates some problems from the point of view of economic sustainability. First of all, the implementation of the blockchain requires both a fixed and an operating cost [39]. The fixed cost concerns the entire technology infrastructure and system implementation among all network participants [53]. In addition, the cost of the skills of managers and of those involved in the management and maintenance of the technology is included [37]. Finally, the operating costs derive from the energy and resource consumption for the actual use of the technology based on the number of the transactions carried out [57]. Furthermore, conflicts of interest can arise between the different members of the network. This could happen when an actor takes opportunistic actions based on information observed in the distributed ledger and can produce economic damage to network participants [53].

Table 3 shows the sustainable and non-sustainable economic issues of blockchain within supply chains.

Table 3. Sustainable and unsustainable economic issues of blockchain in supply chains.

\begin{tabular}{ccc}
\hline Economic Sustainability & References \\
\hline Sustainable Aspects & Collaboration between partners & {$[13,26,55,65-67]$} \\
& Tracking and monitoring of the products & {$[24,26,51,53]$} \\
& Reduction of costs and transaction times & {$[53,59]$} \\
& Improved planning forecast & {$[68]$} \\
Unsustainable Aspects & Cost of implementing, managing and maintaining & {$[37,39,53,57]$} \\
& the technology & {$[53]$} \\
\hline
\end{tabular}

\subsection{Social Sustainability}

Another issue to consider using blockchain in the supply chains is the point of view of social sustainability. Saberi et al. [53] speculates that blockchain in supply chains will more effectively manage economic and environmental sustainability rather than social sustainability. It is certainly very complex to highlight the social benefits achieved in the supply chains that use blockchain, however there are several positive aspects. Some academics argue that as blockchain technology matures, it could solve problems of social inequality and poverty $[69,70]$. First, a blockchain-based supply chain provides a better guarantee of human rights. Blockchain can help supply chains detect unethical suppliers. Making information stable and immutable is one way to build the social sustainability of the supply chain [53]. For example, marine trade in developing countries is often unchecked: this is the case in Indonesia, where there are several questionable practices including overfishing, fraud, illegal fish and human rights violations. Blockchain can help consumers trace the source of their food. Using the blockchain, it is possible to make sustainability indicators more quantifiable and more meaningful [69]. Another case of violation of human rights is related to the diamond trade. For example, Everledger is a company that has created a permanent record of diamond certification and transaction history by creating a digital identity for each diamond in the blockchain network [38]. This guarantees the authentication of the diamond, thus prohibiting the sale of diamonds resulting from illegal practices. Therefore, the transparency of blockchain is a way to achieve greater sustainability and control companies in situations of human rights violations, child labor, inhuman working conditions, corruption and extortion [51]. For example, retailers and governments can retrieve working hours from a blockchain network to judge whether companies are violating overtime limits and whether salaries are being paid to workers on time. These actions will be registered in a blockchain network, which can be considered a tool to support social sustainability certifications [71].

Regarding health and safety in the workplace, blockchain can be used as a distributed ledger for collecting data such as lighting, temperature, humidity, noise and ventilation. These data can be captured and collected by IoT technologies before they can be stored in the blockchain network. Such information can be used to improving the management of the workplace and business performance. 
In addition, data related to staff training and learning in occupational health and safety can be registered in the blockchain network as a basic requirement. In this way, governments can effectively monitor all businesses involved in real time and prevent them from inappropriate behaviors in time. Yet, some workers may feel uncomfortable with wearable devices or worry about being monitored during their work, which can lead to a reluctance to cooperate with their employers [71].

Finally, blockchain can contribute to the improvement of fair working practices. Very often agricultural products such as coffee beans are produced by farmers in developing countries. As the operations in the supply chains are complex and unclear, the market price fluctuates more in some agriculture activities, thus not guaranteeing stable salaries. Blockchain would allow the amount of products collected in a certain period of time to be recorded and made immutable, and allow a fair and stable payment [32].

However, several blockchain technology practices increase the unemployment rate. The digital transformation of our society has transformed the economy and thus the jobs. The blockchain automates many processes and workflows causing the disappearance of intermediate jobs, which add to traditional unemployment. Social sustainability requires the revisiting of obsolete skills and professions [72]. Manufacturing companies that implement blockchain technology can structure secure relationships with their counterparts, eliminating the cost of trust and reducing verification costs. Verification costs arise due to lack of trust between partners. Thus, the real-time transparency of blockchain technology will allow manufacturing company owners to cut manager surveillance costs [73].

Table 4 summarizes the advantages and disadvantages from the point of view of social sustainability that blockchain can provide within the supply chains.

Table 4. Sustainable and unsustainable social issues of blockchain in supply chains.

\begin{tabular}{ccc}
\hline Social Sustainability & References \\
\hline Sustainable Aspects & Guarantee of the human rights & {$[38,51,53,69,71]$} \\
& Health and safety in the workplace & {$[71]$} \\
& Fair working practices & {$[32]$} \\
Unsustainable Aspects & Increase in the unemployment rate & {$[72,73]$} \\
\hline
\end{tabular}

\section{Discussion}

The SLR resulted in several interesting evaluations. First of all, the amount of articles searched within the Scopus database by management journals, using the string that simultaneously contains the word "Blockchain" and the word "Sustainability" (81 articles) are far less than the quantity of articles that contain only the word blockchain (863 articles). The second step further reduced the analyzed sample. Therefore, it is evident that almost $50 \%$ of the "Blockchain" and "Sustainability" sample analyzes the supply chain sector. It can be said that the greatest attention in terms of sustainability is directed to sustainable supply chains. Instead, the absence of articles that analyze the sustainability of supply chains using blockchain from the year 2008 to 2017 is surprising. This means that, so far, there has been little research on this topic, hence it is an area to be carefully analyzed. In the beginning, blockchain was born for the exchange of cryptocurrencies and was only subsequently implemented in other sectors due to its way of achieving decentralization and disintermediation. However, there has recently been a growth trend, with a peak of 22 papers only in the year 2020. Therefore, it was essential to investigate and classify the sustainability aspects related to blockchain in supply chains with a SLR. Regarding the quantity and distribution of these articles among journals, Sustainability ranks first with nine published articles. However, the literature in this area is limited: very few authors have addressed the topic and there are several challenges to be addressed.

Blockchain has features that other similar technologies do not have on the market. First of all, blockchain can be considered as a decentralized database where anyone can record information. The novelty is that these transactions remain immutable and verifiable by anyone with the access keys. This allows anyone to know in real time and in any place the current situation of events and to take 
the consequent corrective actions. Furthermore, this register cannot be modified due to its operating mechanism, which makes it safe and reliable. Indeed, compared to other distributed ledgers, blockchain can integrate perfectly with other emerging technologies such as smart contracts, artificial intelligence, sensors and IoT. Its operating mechanism allows for greater accuracy, greater control, greater safety and immediate sharing of any operation. Therefore, blockchain technology creates a new paradigm based on trust that other distributed ledgers do not guarantee. Starting from these assumptions, blockchain is ideal within supply chains.

From the sustainability point of view, the use of blockchain in the supply chains can guarantee a high level of transparency and better management of resources. In fact, from an environmental point of view, recording the quantity of greenhouse gases produced during the journey will allow different assessments on energy saving to be made. Undoubtedly, blockchain guarantees a standard of authenticity and security to the final consumer that no other system is able to provide in such a precise and verifiable manner. This generates a mechanism for increasing the reputation of the entire supply chain, at the same time it provides social well-being. Furthermore, from an economic point of view, blockchain would allow a reduction in transaction costs by eliminating intermediaries thanks to the use of smart contracts. In addition, the ability to track products and resources allows a reduction in waste, which translates into economic savings. Thanks to the full visibility of the distributed ledger, it is also possible to have transparent collaborations between the partners of the chain. This would ensure greater profits and greater knowledge of the market. The main problem is the implementation of the entire architecture and the research of the specific skills. The skills for blockchain implementation are difficult to find because they are highly specialized. The technology is still in its infancy and not all companies are willing to invest large sums of money. From a social point of view, blockchain would improve the standards of workers, improving the conditions of the workplace and not allowing fraudulent activities such as child slavery. These improvements are present in developing countries where illegal practices are widespread. Certainly, blockchain, like any technological system that automates a process, would cut a lot of jobs. Activities as a middle manager or purchasing manager are destined to disappear, due to machine learning and artificial intelligence algorithms, causing an increase in the unemployment rate.

Therefore, these different scenarios combined with each other can produce both sustainable and unsustainable aspects. At this point what are the weights of these sustainability parameters within the supply chain? Furthermore, what are the effects that each of these parameters has on the supply chain system? Finally, the combination of these aspects what performance measures can produce in companies? Figure 5 metaphorically shows the indeterminacy in current work regarding the assessment of environmental, economic and social impacts using blockchain in supply chains. Some works have used decision-making systems to assess the sustainability of the technology within the supply chain $[26,33,74]$; however, they appear to be mere subjective assessments by experts. In the literature, there are no studies that correlate the different benefits and disadvantages of using blockchain from a sustainability point of view, many of them being theoretical and relying on hypotheses. Finally, the combined use of multiple emerging technologies should not be overlooked. The use of sensors, drones and IoT is essential for the correct use of blockchain. The information recorded in the blockchain must be digitalized in order to guarantee its correct use. Therefore, what is the impact of the combined use of all these emerging technologies? What benefits or problems would they provide? As the current work shows, there is an obvious problem of measuring the impacts that blockchain can carry out. The main reason for this lack is that the blockchain era in supply chains is still in its early stages. Therefore, it is necessary to develop simulators able to simulate case studies and allowing to measure the real sustainability of supply chains using blockchain through key performance indicators. It is only in this way that academics and entrepreneurs can consider the actual usefulness of technology in this specific sector. The measurement on quantitative data will allow us to understand if the advantages will have greater value than the disadvantages and vice versa. Consequently, hypotheses can be advanced on the positive and negative link between blockchain and on the three dimensions 
of sustainability. Indeed, a cost-benefit analysis is needed to answer these questions. Moreover, it is essential to compare the sustainability metrics obtained with traditional supply chain processes-such as warehousing, transport and order management-with the inclusion of blockchain in the supply chain. Further recommendation is to check whether such theories are verified in real business cases. Case studies and quantitative metrics reflecting blockchain in the business world are needed. Other theories could be proposed during the study in the simulation field of blockchain in supply chain. This would allow us to verify new scenarios and understand the real effects on supply chains. In this way, it is possible to effectively evaluate the impacts and performances on sustainability.

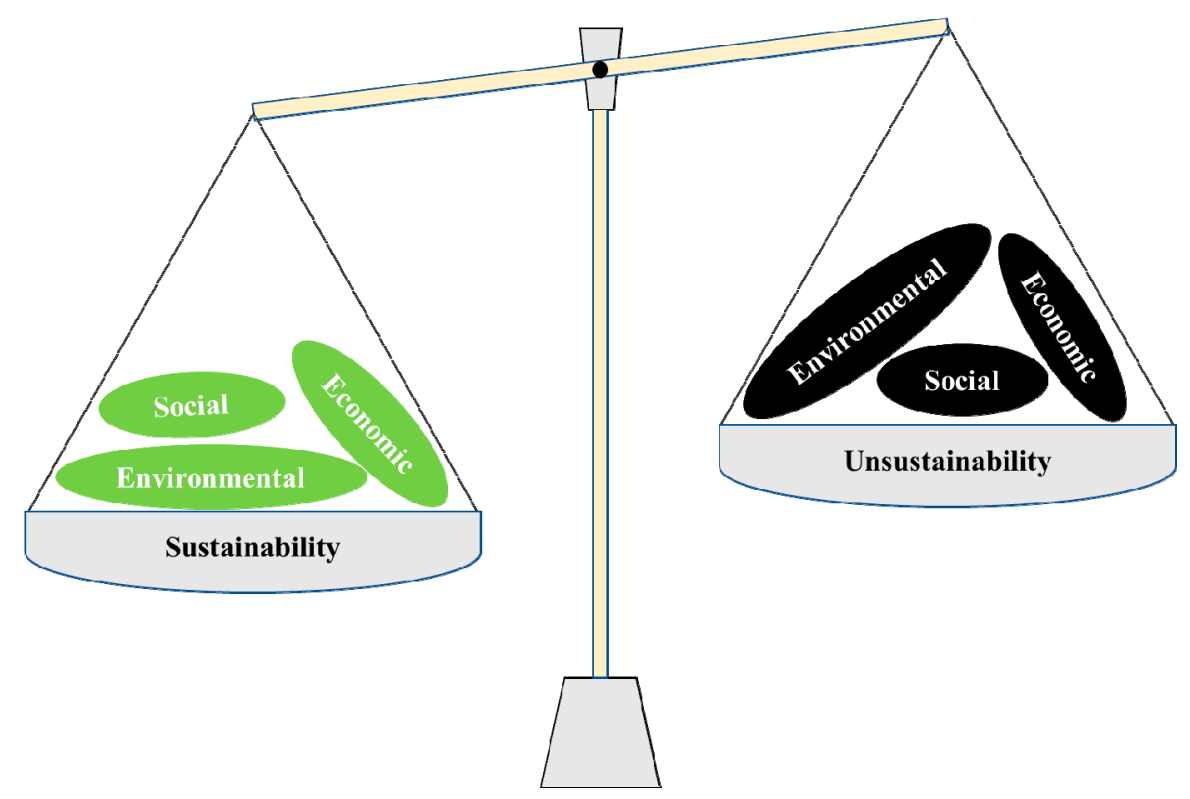

Figure 5. Indeterminacy of indicators on the use of blockchain in supply chains to assess sustainability.

\section{Conclusions and Limitations}

The debate between the applicability of the blockchain in other areas and especially in the supply chain is increasingly studied and discussed $[18,20]$. At this stage, scholars are still trying to understand if the blockchain is feasible in the supply chains $[13,19]$. For this reason, this work proposes to extend the assessment to the adoption of technology in supply chains, also considering the impact on sustainability. Therefore, the proposed work provides an overview of blockchain use in supply chains with regard to the issue of sustainability, showing positive and negative sustainable aspects of the technology. Today, sustainability is a fundamental evaluation criterion to be added to issues related to business performance. Therefore, many practical, managerial and academic implications have been provided. Thanks to this SLR entrepreneurs can evaluate the positive impacts in terms of sustainability of the exploitation of blockchain within the supply chains. The blockchain improves profits by ensuring a reduction in transaction times and costs. In addition, it increases the reputation and image of companies by providing visibility to the practices used in the supply chains. In this way it produces huge sustainable positive economic, social and environmental impacts. The adoption of this technology would allow an increase in transparency towards its partners and final customers. Finally, it would ensure complete and certified monitoring of several activities such as waste management, carbon consumption management, product monitoring and sales forecasting. On the research side, the implications concern the evaluation of new research horizons in the field. The work highlights a research gap in sustainable supply chain management using blockchain. Indeed, the work shows that at the state of the art there is no certainty that the blockchain can bring more benefits than disadvantages in terms of sustainability. Blockchain can be considered a new paradigm for partner management between companies. Moreover, it also promotes the Industry 4.0 development plan. The study shows that few studies have investigated possible sustainability impacts in supply chains using blockchain. It is 
necessary to work further in this direction to achieve real metrics and assessments of the real benefits of this technology. Therefore, it is necessary to extend the literature review to other distributed ledgers to identify the impacts on sustainability in the supply chains and their strengths and weaknesses.

Finally, although the selection of search terms had its own predetermined search direction, this choice may have excluded some articles in which the terms were not present in the title, abstract or keywords. No other search databases were considered, and gray literature was not included. The review has excluded those contributions that have analyzed the relationship between blockchain and supply chain and cited the issue of sustainability with only a partial or limited reasoning. The work is a research agenda that lays the foundations for the aspects of new quantitative metrics on sustainability in the supply chain using blockchain. Furthermore, although future research lines have been proposed, these are entirely theoretical in view of real future developments. The next step will be to identify quantitative metrics related to sustainability. Subsequently, it is necessary to develop mathematical and simulation models to investigate changes in business dynamics and their performance. Therefore, once the blockchain theme has matured within the supply chains, a new literature review will be required to clarify the actual potential for sustainable aspects.

Author Contributions: Conceptualization, A.C. and M.C.; Data curation, V.V.; Formal analysis, V.V.; Methodology, V.V. and A.C.; Project administration, M.C.; Supervision, F.M. and M.C.; Validation, A.C., F.M. and M.C.; Writing-original draft, V.V. and A.C.; Writing-review \& editing, F.M. All authors have read and agreed to the published version of the manuscript.

Funding: This research received no external funding.

Conflicts of Interest: The authors declare no conflict of interest.

\section{References}

1. Nakamoto, S. Bitcoin: A Peer-To-Peer Electronic Cash System. Available online: https://bitcoin.org/bitcoin.pdf (accessed on 10 November 2020).

2. Crosby, M.; Nachiappan; Pattanayak, P.; Verma, S.; Kalyanaraman, V. Blockchain Technology—BEYOND BITCOIN. Berkley Eng. 2016. [CrossRef]

3. Wood, G. Ethereum: A secure decentralised generalised transaction ledger. Ethereum Proj. Yellow Pap. 2014. [CrossRef]

4. Groenfeldt, T. IBM and Maersk Apply Blockchain to Container Shipping; Forbes: New York, NY, USA, 2017.

5. Li, Z.; Bahramirad, S.; Paaso, A.; Yan, M.; Shahidehpour, M. Blockchain for decentralized transactive energy management system in networked microgrids. Electr. J. 2019, 32, 58-72. [CrossRef]

6. Kumar, S.; Talasila, V.; Pasumarthy, R. A novel architecture to identify locations for Real Estate Investment. Int. J. Inf. Manag. 2019. [CrossRef]

7. Kwok, A.O.J.; Koh, S.G.M. Is blockchain technology a watershed for tourism development? Curr. Issues Tour. 2019, 22, 2447-2452. [CrossRef]

8. Oliveira, T.A.; Oliver, M.; Ramalhinho, H. Challenges for connecting citizens and smart cities: ICT, e-governance and blockchain. Sustainability 2020, 12, 2926. [CrossRef]

9. Kshetri, N.; Voas, J. Blockchain-Enabled E-Voting. IEEE Softw. 2018, 35, 95-99. [CrossRef]

10. Sharma, R.; Zhang, C.; Wingreen, S.C.; Kshetri, N.; Zahid, A. Design of Blockchain-based Precision Health-Care Using Soft Systems Methodology. Ind. Manag. Data Syst. 2019, 120, 608-632. [CrossRef]

11. Hughes, A.; Park, A.; Kietzmann, J.; Archer-Brown, C. Beyond Bitcoin: What blockchain and distributed ledger technologies mean for firms. Bus. Horiz. 2019, 62, 273-281. [CrossRef]

12. Wang, Y.; Singgih, M.; Wang, J.; Rit, M. Making sense of blockchain technology: How will it transform supply chains? Int. J. Prod. Econ. 2019, 211, 221-236. [CrossRef]

13. Cole, R.; Stevenson, M.; Aitken, J. Blockchain technology: Implications for operations and supply chain management. Supply Chain Manag. 2019, 24, 469-483. [CrossRef]

14. Michelino, F; Cammarano, A.; Celone, A.; Caputo, M. The linkage between sustainability and innovation performance in IT hardware sector. Sustainability 2019, 11, 4275. [CrossRef]

15. Saleem, A. Automated inventory management systems and its impact on supply chain risk management in manufacturing firms of Pakistan. Int. J. Supply Chain Manag. 2020, 9, 220-231. 
16. Smith, J.R.; Yost, J.; Lopez, H. Electronic data interchange and enterprise resource planning technology in supply chain contracts. Comput. Ind. Eng. 2020, 142, 106330. [CrossRef]

17. Gunasekaran, A.; Ngai, E.W.T.; McGaughey, R.E. Information technology and systems justification: A review for research and applications. Eur. J. Oper. Res. 2006, 173, 957-983. [CrossRef]

18. Fosso Wamba, S.; Kala Kamdjoug, J.R.; Epie Bawack, R.; Keogh, J.G. Bitcoin, Blockchain and Fintech: A systematic review and case studies in the supply chain. Prod. Plan. Control. 2020, 31, 115-142. [CrossRef]

19. Queiroz, M.M.; Telles, R.; Bonilla, S.H. Blockchain and supply chain management integration: A systematic review of the literature. Supply Chain Manag. 2019, 25, 241-254. [CrossRef]

20. Wang, Y.; Han, J.H.; Beynon-Davies, P. Understanding blockchain technology for future supply chains: A systematic literature review and research agenda. Supply Chain Manag. 2019, 24, 62-84. [CrossRef]

21. Hasan, H.; AlHadhrami, E.; AlDhaheri, A.; Salah, K.; Jayaraman, R. Smart contract-based approach for efficient shipment management. Comput. Ind. Eng. 2019, 136, 149-159. [CrossRef]

22. Lezoche, M.; Panetto, H.; Kacprzyk, J.; Hernandez, J.E.; Alemany Díaz, M.M.E. Agri-food 4.0: A survey of the Supply Chains and Technologies for the Future Agriculture. Comput. Ind. 2020, 117, 103187. [CrossRef]

23. Ivanov, D.; Dolgui, A.; Sokolov, B. The impact of digital technology and Industry 4.0 on the ripple effect and supply chain risk analytics. Int. J. Prod. Res. 2019, 57, 829-846. [CrossRef]

24. Astill, J.; Dara, R.A.; Campbell, M.; Farber, J.M.; Fraser, E.D.G.; Sharif, S.; Yada, R.Y. Transparency in food supply chains: A review of enabling technology solutions. Trends Food Sci. Technol. 2019, 91, $240-247$. [CrossRef]

25. Sharma, R.; Kamble, S.S.; Gunasekaran, A.; Kumar, V.; Kumar, A. A systematic literature review on machine learning applications for sustainable agriculture supply chain performance. Comput. Oper. Res. 2020, 119, 104926. [CrossRef]

26. Bai, C.; Sarkis, J. A supply chain transparency and sustainability technology appraisal model for blockchain technology. Int. J. Prod. Res. 2020, 58, 2142-2162. [CrossRef]

27. Schmidt, C.G.; Wagner, S.M. Blockchain and supply chain relations: A transaction cost theory perspective. J. Purch. Supply Manag. 2019, 25, 100552. [CrossRef]

28. Pournader, M.; Shi, Y.; Seuring, S.; Koh, S.C.L. Blockchain applications in supply chains, transport and logistics: A systematic review of the literature. Int. J. Prod. Res. 2020, 58, 2063-2081. [CrossRef]

29. Kamilaris, A.; Fonts, A.; Prenafeta-Boldv, F.X. The rise of blockchain technology in agriculture and food supply chains. Trends Food Sci. Technol. 2019, 91, 640-652. [CrossRef]

30. Hastig, G.M.; Sodhi, M.M.S. Blockchain for Supply Chain Traceability: Business Requirements and Critical Success Factors. Prod. Oper. Manag. 2020, 29, 935-954. [CrossRef]

31. Montecchi, M.; Plangger, K.; Etter, M. It's real, trust me! Establishing supply chain provenance using blockchain. Bus. Horiz. 2019, 62, 283-293. [CrossRef]

32. Tang, C.S.; Veelenturf, L.P. The strategic role of logistics in the industry 4.0 era. Transp. Res. Part. E Logist. Transp. Rev. 2019, 129, 1-11. [CrossRef]

33. Yadav, S.; Singh, S.P. Blockchain critical success factors for sustainable supply chain. Resour. Conserv. Recycl. 2020, 152, 104505. [CrossRef]

34. Farooque, M.; Jain, V.; Zhang, A.; Li, Z. Fuzzy DEMATEL analysis of barriers to Blockchain-based life cycle assessment in China. Comput. Ind. Eng. 2020, 147, 106684. [CrossRef]

35. Cearley, D.; Jones, N.; Smith, D.; Burke, B.; Chandrasekaran, A.; Lu, C.; Panetta, K. Gartner Top 10 Strategic Technology Trends for 2020_Smarter with Gartner; Gartner: Stamford, CT, USA, 2019.

36. Cammarano, A.; Michelino, F.; Lamberti, E.; Caputo, M. Investigating technological strategy and relevance of knowledge domains in R\&D collaborations. Int. J. Technol. Manag. 2019, 79, 60-83. [CrossRef]

37. Kamble, S.; Gunasekaran, A.; Arha, H. Understanding the Blockchain technology adoption in supply chains-Indian context. Int. J. Prod. Res. 2019, 57, 2009-2033. [CrossRef]

38. Choi, T.M. Blockchain-technology-supported platforms for diamond authentication and certification in luxury supply chains. Transp. Res. Part. E Logist. Transp. Rev. 2019, 128,17-29. [CrossRef]

39. Choi, T.M.; Luo, S. Data quality challenges for sustainable fashion supply chain operations in emerging markets: Roles of blockchain, government sponsors and environment taxes. Transp. Res. Part. E Logist. Transp. Rev. 2019, 131, 139-152. [CrossRef]

40. Kittipanya-ngam, P.; Tan, K.H. A framework for food supply chain digitalization: Lessons from Thailand. Prod. Plan. Control. 2020, 31, 158-172. [CrossRef] 
41. Yang, C.S. Maritime shipping digitalization: Blockchain-based technology applications, future improvements, and intention to use. Transp. Res. Part. E Logist. Transp. Rev. 2019, 131, 108-117. [CrossRef]

42. Ciruela-Lorenzo, A.M.; Del-Aguila-Obra, A.R.; Padilla-Meléndez, A.; Plaza-Angulo, J.J. Digitalization of agri-cooperatives in the smart agriculture context. Proposal of a digital diagnosis tool. Sustainability 2020, 12, 1325. [CrossRef]

43. Chang, Y.; Iakovou, E.; Shi, W. Blockchain in global supply chains and cross border trade: A critical synthesis of the state-of-the-art, challenges and opportunities. Int. J. Prod. Res. 2020, 58, 2082-2099. [CrossRef]

44. Bavassano, G.; Ferrari, C.; Tei, A. Blockchain: How shipping industry is dealing with the ultimate technological leap. Res. Transp. Bus. Manag. 2020, 34, 100428. [CrossRef]

45. Jensen, T.; Hedman, J.; Henningsson, S. How TradeLens delivers business value with blockchain technology. MIS Q. Exec. 2019, 18, 221-243. [CrossRef]

46. Mattke, J.; Hund, A.; Maier, C.; Weitzel, T. How an enterprise blockchain application in the U.S. Pharmaceuticals supply chain is saving lives. MIS Q. Exec. 2019, 18, 246-261. [CrossRef]

47. Longo, F.; Nicoletti, L.; Padovano, A.; d'Atri, G.; Forte, M. Blockchain-enabled supply chain: An experimental study. Comput. Ind. Eng. 2019, 136, 57-69. [CrossRef]

48. Malik, S.; Kanhere, S.S.; Jurdak, R. ProductChain: Scalable blockchain framework to support provenance in supply chains. In Proceedings of the NCA 2018-2018 IEEE 17th International Symposium on Network Computing and Applications, Cambridge, MA, USA, 1-3 November 2018.

49. Pedersen, A.B.; Risius, M.; Beck, R. A ten-step decision path to determine when to use blockchain technologies. MIS Q. Exec. 2019, 18, 99-115. [CrossRef]

50. Manupati, V.K.; Schoenherr, T.; Ramkumar, M.; Wagner, S.M.; Pabba, S.K.; Inder Raj Singh, R. A blockchain-based approach for a multi-echelon sustainable supply chain. Int. J. Prod. Res. 2020, 58, 2222-2241. [CrossRef]

51. Helo, P.; Hao, Y. Blockchains in operations and supply chains: A model and reference implementation. Comput. Ind. Eng. 2019, 136, 242-251. [CrossRef]

52. Zhao, G.; Liu, S.; Lopez, C.; Lu, H.; Elgueta, S.; Chen, H.; Boshkoska, B.M. Blockchain technology in agri-food value chain management: A synthesis of applications, challenges and future research directions. Comput. Ind. 2019, 109, 83-99. [CrossRef]

53. Saberi, S.; Kouhizadeh, M.; Sarkis, J.; Shen, L. Blockchain technology and its relationships to sustainable supply chain management. Int. J. Prod. Res. 2019, 57, 2117-2135. [CrossRef]

54. Tranfield, D.; Denyer, D.; Smart, P. Towards a Methodology for Developing Evidence-Informed Management Knowledge by Means of Systematic Review. Br. J. Manag. 2003, 14, 207-222. [CrossRef]

55. Tan, B.Q.; Wang, F.; Liu, J.; Kang, K.; Costa, F. A blockchain-based framework for green logistics in supply chains. Sustainability 2020, 12, 4656. [CrossRef]

56. Kouhizadeh, M.; Sarkis, J. Blockchain practices, potentials, and perspectives in greening supply chains. Sustainability 2018, 10, 3652. [CrossRef]

57. Esmaeilian, B.; Sarkis, J.; Lewis, K.; Behdad, S. Blockchain for the future of sustainable supply chain management in Industry 4.0. Resour. Conserv. Recycl. 2020, 163, 105064. [CrossRef]

58. Kim, J.S.; Shin, N. The impact of blockchain technology application on supply chain partnership and performance. Sustainability 2019, 11, 6181. [CrossRef]

59. Kouhizadeh, M.; Sarkis, J.; Zhu, Q. At the nexus of blockchain technology, the circular economy, and product deletion. Appl. Sci. 2019, 9, 1712. [CrossRef]

60. Zhang, A.; Zhong, R.Y.; Farooque, M.; Kang, K.; Venkatesh, V.G. Blockchain-based life cycle assessment: An implementation framework and system architecture. Resour. Conserv. Recycl. 2020,152, 104512. [CrossRef]

61. Fairley, P. Blockchain world-Feeding the blockchain beast if bitcoin ever does go mainstream, the electricity needed to sustain it will be enormous. IEEE Spectr. 2017, 54, 36-59. [CrossRef]

62. Kouhizadeh, M.; Saberi, S.; Sarkis, J. Blockchain technology and the sustainable supply chain: Theoretically exploring adoption barriers. Int. J. Prod. Econ. 2020, 231, 107831. [CrossRef]

63. Giungato, P.; Rana, R.; Tarabella, A.; Tricase, C. Current trends in sustainability of bitcoins and related blockchain technology. Sustainability 2017, 9, 2214. [CrossRef]

64. Li, A.; Wei, X.; He, Z. Robust proof of stake: A new consensus protocol for sustainable blockchain systems. Sustainability 2020, 12, 2824. [CrossRef] 
65. Michelino, F.; Lamberti, E.; Cammarano, A.; Caputo, M. Open models for innovation: An accounting-based perspective. Int. J. Technol. Manag. 2015, 68, 99-121. [CrossRef]

66. Kamble, S.S.; Gunasekaran, A.; Gawankar, S.A. Achieving sustainable performance in a data-driven agriculture supply chain: A review for research and applications. Int. J. Prod. Econ. 2020, 219, 179-194. [CrossRef]

67. Michelino, F.; Cammarano, A.; Lamberti, E.; Caputo, M. Measurement of open innovation through intellectual capital flows: Framework and application. Int. J. Intell. Enterp. 2014, 2, 213-235. [CrossRef]

68. Lahkani, M.J.; Wang, S.; Urbański, M.; Egorova, M. Sustainable B2B E-commerce and blockchain-based supply chain finance. Sustainability 2020, 12, 3968. [CrossRef]

69. Kshetri, N. 1 Blockchain's roles in meeting key supply chain management objectives. Int. J. Infor. Manag. 2018, 39, 80-89. [CrossRef]

70. Tapscott, D.; Tapscott, A. How blockchain will change organizations. MIT Sloan Manag. Rev. 2017. [CrossRef]

71. Venkatesh, V.G.; Kang, K.; Wang, B.; Zhong, R.Y.; Zhang, A. System architecture for blockchain based transparency of supply chain social sustainability. Robot. Comput. Integr. Manuf. 2020, 63, 101896. [CrossRef]

72. Marsal-Llacuna, M.L. The people's smart city dashboard (PSCD): Delivering on community-led governance with blockchain. Technol. Forecast. Soc. Chang. 2020, 158, 120150. [CrossRef]

73. Ko, T.; Lee, J.; Ryu, D. Blockchain technology and manufacturing industry: Real-time transparency and cost savings. Sustainability 2018, 10, 4274. [CrossRef]

74. Rahmanzadeh, S.; Pishvaee, M.S.; Rasouli, M.R. Integrated innovative product design and supply chain tactical planning within a blockchain platform. Int. J. Prod. Res. 2020, 58, 2242-2262. [CrossRef]

Publisher's Note: MDPI stays neutral with regard to jurisdictional claims in published maps and institutional affiliations. 